\title{
LA ACTUACIÓN DE LOS EJECUTORES COACTIVOS MUNICIPALES: ¿DELITO DE ABUSO DE AUTORIDAD?
}

\section{César Augusto Nakazaki Servigón}

Profesor de Derecho Penal y Procesal Penal en la Academia de la Magistratura. Presidente de la Comisión de Diagnóstico del Proceso Penal del Congreso de la República.

\section{INTRODUCCIÓN}

$\mathrm{E}$ $n$ el umbral del siglo XXI, y en medio del profundo debate que genera la necesidad de construir o reconstruir las instituciones, a través de las cuales la generación de peruanos adultos de hoy tenemos la responsabilidad de establecer las columnas del Perú de nuestros hijos y nietos, es indispensable tomar conciencia de cómo la "normal" y "aceptada" violación de la ley es parte de la vida cotidiana del país.

En el Perú la ley no sólo no se cumple, sino, lo que es más grave, se justifica! el no cumplirla.

Un sencillo y significativo ejemplo se tiene en la experiencia que constituye apreciar, pasada la medianoche, en una esquina con semáforo el comportamiento no de la gran mayoría de conductores que no se detendrán ante la luz roja, sino del chofer del vehículo que se encuentra detrás del único conductor que ha parado el automóvil respetando la norma de tránsito ante la luz roja del semáforo; ¿el chofer que está detrás de aquél comprenderá su actitud, la aceptará, o empezará por expresar su disconformidad con gestos y palabras que podemos imaginar o recordar?

De la "cultura" de no respeto a la ley como parte de mi experiencia profesional he examinado el comportamiento de ejecutores coactivos de distintas municipalidades del país que realizan actos de ejecución coactiva en cualquier lugar del Perú que deci- 
dan, irrogándose una competencia nacional que en el orden jurídico no se les reconoce.

Ejecutores coactivos municipales de distintas provincias y distritos del país llegan a Lima y en su condición de tales proceden a exigir a instituciones del sistema bancario, financiero o bursátil, que implementen las medidas de ejecución coactiva que dispongan sin importar el lugar en el que se encuentre la municipalidad a la que pertenecen.

A continuación presento el resultado del examen jurídico de tal comportamiento de estos funcionarios públicos, a fin de demostrar que resulta un ejemplo nacional de la "cultura" de la ilegalidad que incluso puede llegar a configurar la comisión masiva del delito de abuso de autoridad como instrumento utilizado para el ejercicio de la potestad de cobranza coactiva de una gran mayoría de municipalidades del Perú.

\section{LA FIJACIÓN DEL CRITERIO DE DETERMINACIÓN DE LA COMPETENCIA DEL EJECUTOR COACTIVO MUNICIPAL}

La competencia es el ámbito en el cual un funcionario público puede ejercitar con regularidad, legítimamente, la potestad (poder + deber) de la cual ha sido investido en la ley.

El análisis del caso presentado parte de la premisa que, conforme al derecho constitucional, al derecho administrativo y al derecho procesal, solamente mediante la ley se fija la competencia de un funcionario público, máxime si la potestad (poder + deber) cuyo ámbito de aplicación se determina, tiene como consecuencia afectar derechos fundamentales de los administrados.
El examen dogmático jurídico del sistema constitucional, el sistema administrativo y el sistema procesal permite verificar cómo consagran -con absoluta claridad- la regla del sometimiento de los funcionarios públicos a la ley.

En los tres sistemas jurídicos el principio de legalidad constituye un límite formal al ius imperium en todas sus manifestaciones y niveles de ejercicio.

En el orden jurídico peruano nadie tiene solamente poder, sino potestad, es decir, poder + deber, siendo el primero de los deberes del funcionario público su sometimiento a la ley.

La potestad solamente se ejerce en los casos y formas establecidas en la ley.

El ejecutor coactivo es definido por el artículo 3 de la ley 26979, Ley de Procedimientos de Ejecución Coactiva, como el titular del proceso coactivo en representación de la municipalidad provincial o distrital.

Las acciones de coerción del proceso de cobranza coactiva y del proceso cautelar, que asegura el resultado del primero. son realizados por el ejecutor coactivo en representación de la municipalidad provincial o distrital a la que pertenece.

En la Ley de Procedimientos de Ejecución Coactiva no hay una regla procesal de determinación de la competencia de forma específica, por lo que se tiene que recurrir a los métodos de interpretación teleológica y sistemática para, a través del examen de otras disposiciones de la ley 26979, encontrar el criterio de determinación de la competencia de un ejecutor coactivo, que evidentemente existe ya que no hay funcionario o servidor público sin ámbito de competencia funcional.

El artículo 1 establece el marco legal de los actos de ejecución coactiva, que realizan todas las entidades que forman la administración pública nacional, y entre las cuales se encuentran las municipalidades. 
La municipalidad es la que tiene la potestad de realizar los actos de ejecución coactiva, la que ejercita a través de un representante, el ejecutor coactivo, conforme al artículo 3 de la Ley de Procedimientos de Ejecución Coactiva.

Consecuentemente el ejecutor coactivo, como representante de la municipalidad, realizará las acciones de coerción en el ámbito de competencia que tenga la municipalidad provincial o distrital.

El representante no tiene un ámbito de realización de los actos objeto de la representación mayor al que corresponde al representado; es decir, el ejecutor coactivo no puede tener un ámbito de competencia para llevar a cabo los actos de coerción mayor que el de la municipalidad a la que representa.

La municipalidad fija su ámbito de competencia utilizando el criterio del territorio conforme se establece en el artículo 6 de la Ley Orgánica de Municipalidades.

El criterio de determinación del ámbito de competencia de la municipalidad es el territorio que corresponde a la provincia, al distrito, o a la porción de territorio delimitada, según se trate de una municipalidad provincial, de una municipalidad distrital, o de una municipalidad delegada, respectivamente.

Por ejemplo, la Municipalidad Distrital de San Buenaventura tiene su ámbito de competencia en el territorio del distrito de San Buenaventura.

El ejecutor coactivo de la Municipalidad Distrital de San Buenaventura tiene como ámbito de competencia, para la realización de los actos de coerción, el que corresponde a dicha municipalidad distrital, o sea, el territorio del distrito de San Buenaventura.

El ejecutor coactivo del distrito de San Buenaventura no puede realizar actos de coerción fuera del ámbito de competencia territorial de la municipalidad distrital que representa, pues, como se reitera, el ejecutor coactivo solamente puede actuar en el territorio donde tiene competencia la municipalidad a la que pertenece.

La posición de que el ejecutor coactivo municipal solamente puede realizar actos de coerción en el ámbito de competencia territorial de la municipalidad que representa, se ve fortalecida si se recurre, vía la analogía, al Reglamento del Procedimiento de Cobranza Coactiva que contiene la resolución 016-97/Sunat, es decir, a la normatividad que regula la actuación de los ejecutores coactivos de la Sunat.

El artículo 3 del reglamento, a diferencia de la normatividad que regula la actuación de los ejecutores coactivos municipales, establece una regla para la determinación de la competencia de los ejecutores coactivos de la Sunat.

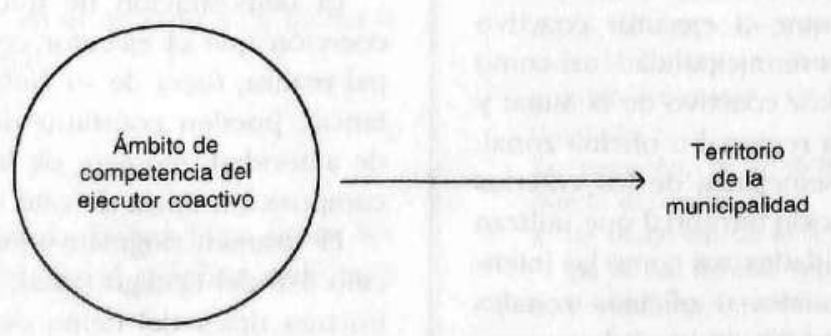


El Ejecutor ejercerá sus facultades respecto a los deudores pertenecientes a las Intendencias Regionales $u$ Oficinas Zonales para las que fue designado por la Sunat, pudiendo solicitar que los Ejecutores de otras Intendencias $u$ Oficinas Zonales donde se encuentren los bienes o derechos de los deudores de su competencia, efectúen los actos y diligencias necesarias para el cobro de la deuda (subrayado del autor del estudio).

La norma procesal recoge el criterio del territorio para fijar el ámbito de competencia de los ejecutores coactivos de la Sunat, ya que éstos solamente pueden realizar los actos de coerción respecto de los deudores que domicilien en el territorio asignado a la intendencia regional o a la oficina zonal para la que han sido designados.

El territorio de la intendencia regional o de la oficina zonal de la Sunat establece el ámbito de competencia del ejecutor coactivo.

Es procedente la utilización analógica de la disposición legal comentada, ya que se verifica la relación de identidad o de semejanza que exige el método analógico entre los ejecutores coactivos municipales y los ejecutores coactivos de la Sunat en tres factores:

- Identidad o semejanza de las funciones de coerción de los ejecutores coactivos municipales y de los ejecutores coactivos de la Sunat.

- Identidad o semejanza de la vinculación de dependencia y representación que existe entre el ejecutor coactivo municipal y la municipalidad, así como entre el ejecutor coactivo de la Sunat y la intendencia regional u oficina zonal.

- Identidad o semejanza de los criterios de determinación territorial que utilizan las municipalidades, así como las intendencias regionales $\mathrm{u}$ oficinas zonales para establecer sus ámbitos de competencia.
En consecuencia es válido aplicar, por analogía, a los ejecutores coactivos de las municipalidades el criterio de determinación de la competencia por el territorio que se emplea en el caso de los ejecutores coactivos de la Sunat.

En nuestro ejemplo el ejecutor coactivo de la Municipalidad Distrital de San Buenaventura no puede realizar actos de coerción, como el de implementación de un embargo respecto de bienes muebles que se encuentran en Lima, ya que esta ciudad no se encuentra en el ámbito de competencia territorial de la mencionada municipalidad.

El ejecutor coactivo de la Municipalidad Distrital de San Buenaventura para implementar una medida cautelar, por ejemplo sobre acciones de una entidad bancaria que se encuentra en Lima, tendría que recurrir a un exhorto o comisión para que un ejecutor coactivo municipal competente por el territorio sea el que realice el acto de coerción.

\section{LA REALIZACIÓN DE ACTOS DE COERCIÓN POR EL EJECUTOR COACTIVO MUNICIPAL FUERA DE SU ÁMBITO DE COMPETENCIA PUEDE CONFIGURAR LA COMISIÓN DEL DELITO DE ABUSO DE AUTORIDAD GENÉRICO}

La demostración de que los actos de coerción que el ejecutor coactivo municipal realiza, fuera de su ámbito de competencia, pueden constituir delito de abuso de autoridad, requiere de la fijación de la composición típica de este ilícito penal.

El examen dogmático-jurídico del artículo 376 del Código Penal, presenta la estructura típica del delito de abuso de autoridad genérico siguiente: 
Estructura típica del delito de abuso de autoridad genérico o innominado

1. El bien juridico :

2. El sujeto activo:

3. La acción típica :

4. El elemento subjetivo:
La administración pública, especificamente la corrección y la legalidad de los actos de los funcionarios públicos.

El agente de este delito es el funcionario público.

Cometer u ordenar la realización de un acto arbitrario en perjuicio de alguien.

Dolo.

\subsection{Operación de tipificación del becho de la realización de actos de coerción por el ejecutor coactivo municipal, fuera del ámbito de competencia en el tipo penal de abuso de autoridad}

\section{Bien jurídico}

El bien jurídico tutelado, que se afecta con el hecho objeto de estudio, es la exigencia de que la administración tributaria municipal desarrolle su actuación con regularidad y legalidad a través de un ejecutor coactivo.

\section{Sujeto activo}

El ejecutor coactivo municipal tiene la condición de funcionario público, conforme se establece en el artículo 2 , inciso c de la ley 26979 y en el artículo 425, inciso 6 del Código Penal.

\section{Acción típica}

La captación de la conducta típica requiere de establecer el significado de acto arbitrario.

El concepto de acto arbitrario no puede ser determinado por el derecho penal, da- do su carácter fragmentario y secundario (en orden de intervención, no de importancia), por lo que en la parte especial del derecho penal no lo desarrolla adecuadamente; siendo una excepción a este insuficiente tratamiento el caso del maestro italiano Giuseppe Maggiore, quien a pesar del tiempo transcurrido sigue vigente gracias a la profundidad de análisis que da trabajar la dogmática jurídico-penal sobre el soporte que constituye la filosofía del derecho.

Maggiore se refiere al acto arbitrario en los siguientes términos:

El acto arbitrario es todo acto que concreta algún abuso de los poderes atribuidos al funcionario público...

Acto arbitrario es el acto contrario a los deberes del cargo. Esto puede acaecer de dos maneras: o porque el acto constituye una violación de la ley (ilegitimidad), o porque, sin haber violación de la ley propiamente dicha, el acto constituye un ejercicio abusivo de funciones discrecionales, que no pueden ser materia de inspección de legitimidad...

En resumen, la arbitrariedad de un acto puede depender:

a. de violación de la ley o de inobservancia de las formas legales prescritas;

b. de incompetencia relativa, es decir, de exceso en los límites de la competencia... 
c. cle abuso de los poderes discrecionales. (Derecho penal, Parte especial. Vol. III, De los delitos en particular. Bogotá: Editorial Temis, 1972, p. 273).

El ejecutor coactivo no es competente para realizar actos de coerción fuera del ámbito de competencia territorial de la municipalidad a la que representa, por lo que la afectación de los derechos de las personas que genere mediante actos de ejecución coactiva en lugares donde es incompetente, puede configurar la acción típica del abuso de autoridad, es decir, el acto arbitrario.

Dolo

Si el ejecutor coactivo realiza los actos de coerción fuera del ámbito de su competencia con conocimiento y voluntad, los elementos de la parte objetiva del tipo, es decir que es funcionario público, que realiza un acto de coerción fuera de su ámbito de competencia y que perjudica los derechos de un administrado, actúa con el dolo que constituye la parte subjetiva del tipo penal de abuso de autoridad genérico.

Sin perjuicio de los problemas de faz negativa del delito, como el error, que podrían quitar contenido penal a esta práctica de los ejecutores coactivos municipales en los casos en que pudiesen presentarse, lo cierto es que constituye definitivamente una conducta ilícita a la que recurren masivamente muchos de estos funcionarios públicos en el ejercicio de la potestad de cobranza coactiva, que llega frecuentemente, incluso, al delito de abuso de autoridad innominado.

\section{Bibliografia}

GONZALES CUSSAC, José Luis

El delito de prevaricación de autoridades y funcionarios püblicos. 2a. edición. Colección Los Delitos. Valencia (Espana): Editorial Tirant lo Blanch, 1997.

MAGGIORE, Giussepe

Derecho penal, Parte especial. Vol. III. Bogotá: Editorial Temis, 1972.

MONTERO AROCA, Juan; Manuel ORTELLS RAMOS, Juan Luis GÓMEZ COLOMER y Alberto MONTÓN REDONDO

Derecho jurisdiccional. Tomo I. Parte general. Barcelona: J.M. Bosch Editor S.A., 1994.

PALOMAR OLMEDA, Alberto Derecbo de la función pública. 5a. edición. Madrid: Editorial Dykinson, 2000.

ROJAS VARGAS, Fidel

Delitos contra la administración pública. Lima: Editorial Grijley, 1999. 